\title{
Erratum to: The Disability Paradox Revisited: Quality of Life and Family Caregiving in Pediatric Cerebral Palsy
}

\author{
Carlos Carona $\cdot$ Marco Pereira $\cdot$ Helena Moreira • \\ Neuza Silva $\cdot$ Maria Cristina Canavarro
}

Published online: 17 September 2013

(c) Springer Science+Business Media New York 2013

\section{Erratum to: J Child Fam Stud \\ DOI 10.1007/s10826-012-9659-0}

This erratum is an amendment to the statistical interpretation and conceptual integration of a specific finding reported in the aforementioned article.

In this study, caregiving Uplifts were found to moderate the associations between certain types of caregiving Burden and specific quality of life (QL) domains. These moderating effects were graphically depicted in Figs. 1 and 2. In the first case, caregiving Uplifts moderated the association between Objective Burden and Psychological $\mathrm{QL}$ and that positive influence was observed across all burden conditions (i.e., regardless of the presence of adversity). As for the second case, caregiving Uplifts moderated the association between Relationship Burden and Social QL, but that positive influence was observed only in the adverse context of medium-high burden (i.e., the moderating variable did not operate in low adversity conditions).

This is to say that caregiving Uplifts operated as a "resource" in the former case and as a "protective factor" in the later. Therefore, caregiving Uplifts should be regarded as a "resource" or a "protective factor" depending on their associations with those specific types of burden and QL domains.

The online version of the original article can be found under doi: 10.1007/s10826-012-9659-0.

C. Carona $(\bowtie)$

Faculty of Psychology and Education Sciences, Cognitive

Psychology Institute, Coimbra University, Rua do Colégio Novo,

Apartado 6153, 3001-802 Coimbra, Portugal

e-mail: ccarona@fpce.uc.pt

M. Pereira - H. Moreira $\cdot$ N. Silva $\cdot$ M. C. Canavarro Institute of Cognitive Psychology, Vocational and Social

Development, Coimbra University, Coimbra, Portugal 